\title{
CASAMENTO FANTASMA?- A PRESENÇA DOS ANCESTRAIS ATRAVÉS DE IMAGENS
}

\section{Aina Azevedo 1}

Mangaliso Kubheka completou 60 anos em 2010. Em sua festa de aniversário, Bongiwe, a neta mais velha, ficou ao seu lado nos momentos mais importantes. ${ }^{2} \mathrm{~A}$ esposa de Mangaliso havia falecido há muitos anos e a neta fora escolhida para representá-la em cerimônias como aquela. A escolha, no entanto, não era casual ${ }^{3}$. Ao perguntar o que ocorreria acaso Bongiwe fosse criança, me responderam que mesmo assim era ela quem deveria estar no lugar da avó, como havia ocorrido, aliás, em 1999, por ocasião da celebração do chamado white wedding (casamento branco).

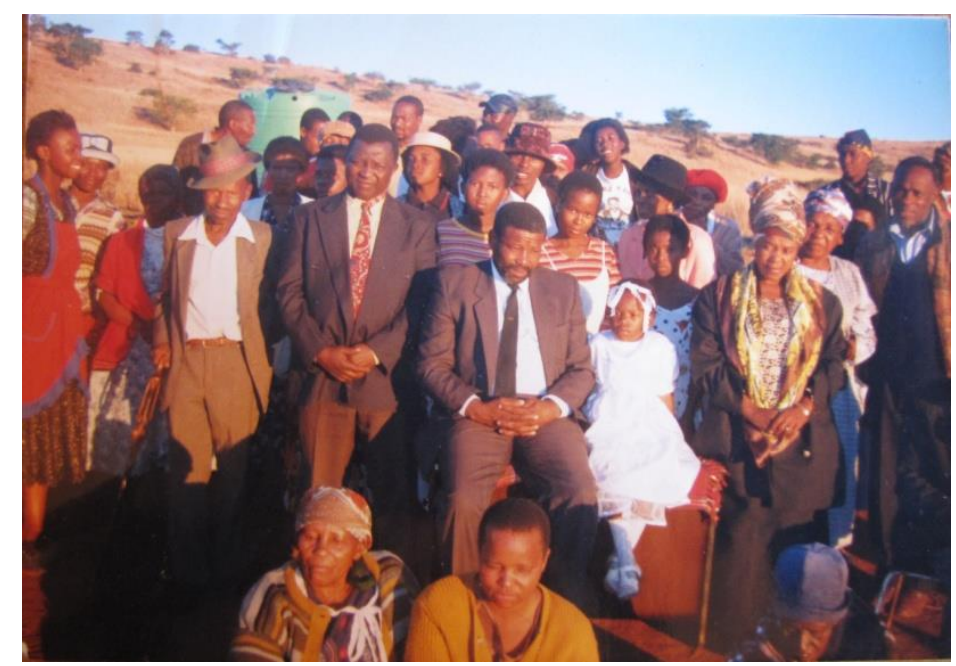

White wedding

Fonte: Arquivo Kubheka.

\footnotetext{
${ }^{1}$ Universidade de Brasília, Brasil e University of Aberdeen, United Kingdom.

${ }^{2} \mathrm{O}$ presente artigo é fruto da tese do doutoramento "Conquistas cosmológicas - pessoa, casa e casamento entre os Kubheka de KwaZulu - Natal e Gauteng (Azevedo, 2013), disponível em: http://repositorio.unb.br/handle/10482/15094. Nesta ocasião, agradeço à Capes e ao CNPq pelas bolsas de doutorado concedidas e à Capes, particularmente, pela bolsa sanduíche (PDEE) - todas fundamentais para a realização da minha tese de doutorado e, consequentemente, do presente artigo. Atualmente, sou bolsista de pós-Doutorado da CAPES, a quem agradeço mais uma vez.

${ }^{3}$ Conforme Radcliffe-Brown, o "princípio estrutural" fundamental aqui é o de que com o tempo uma geração é substituída pela de seus netos. A estrutura social baseada em gerações diz que a relação entre as gerações imediatas é de desigualdade social, autoridade, proteção, respeito e dependência. Já a relação entre as gerações alternadas é de familiaridade, cordialidade e igualdade. Avós e netos se incluem na mesma geração mediante essa "fusão das gerações alternadas", quando surge a possibilidade do casamento (1982: 39-41).
} 
Em busca de fotografias do white wedding, visitei a casa da filha mais velha de Mangaliso, Thembeni, mãe de Bongiwe, na township de Madadeni. Enquanto remexíamos nos retratos antigos, além da fotografia do white wedding, encontramos um retrato de outro casamento. Em ambos os casos, se tratava de uma celebração na qual nem todos os cônjuges estavam vivos. No segundo caso, em particular, ambos os cônjuges haviam falecido, algo que poderia ser percebido por meio dos ramos de árvores que o noivo e a noiva traziam nas mãos, indicando que estavam no lugar de pessoas falecidas.

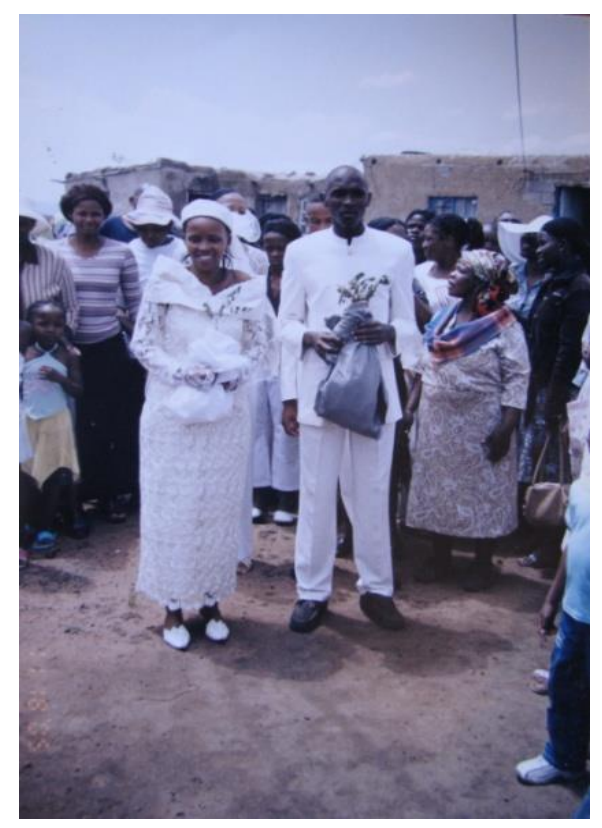

Casamento de pessoas falecidas Fonte: Arquivo Kubheka.

Naturalmente, o encontro com essas fotografias motivou uma série de conversas a respeito do casamento. Ver casamentos de pessoas falecidas realizados através de outros era absolutamente fascinante para mim. Quando perguntei se era comum atenderem a cerimônias como aquelas, me responderam afirmativamente, afinal, "sempre que alguém pode fazer um casamento, faz", acrescentaram. Nossa conversa prosseguia enquanto casamentos pregressos eram relembrados, casamentos de pessoas falecidas eram explicados e, para a minha surpresa, um casamento futuro começava a ser planejado. 
Thembeni comentou que no ano corrente (2011) desejava realizar a parte faltante do casamento de seus pais. O casamento de Mangaliso e sua esposa ainda não havia sido concluído. A morte trágica da noiva não anulava a eminência dos rituais como fora o caso do white wedding anos atrás. Ainda faltava algo: Thembeni dizia que a noiva deveria presentear o noivo e sua família, evento conhecido como umabo. Nas suas contas, 52 pessoas precisavam ser presenteadas com cobertores, travesseiros e esteiras. Thembeni imaginava que em junho ou julho daquele ano conseguiria fazer o ritual.

Até o encontro com a fotografia do white wedding e a perspectiva da realização do umabo, as questões que motivavam a minha pesquisa ainda não se relacionavam ao casamento. A exemplo de tantas outras diásporas sofridas pela população negra sulafricana durante e após o apartheid, a história da família Kubheka, marcada por mudanças forçadas entre áreas rurais e townships, conduzia a investigação. Buscava visitar os lugares em que moraram - distantes temporal e espacialmente - e as relações que poderiam existir entre eles na vida atual dos Kubheka, quando finalmente haviam conquistado uma fazenda por meio do programa de Land Reform (Reforma da Terra) sul-africano e retornado à área rural.

A família Kubheka foi minha anfitriã na África do Sul ao longo dos anos de 2010 e 2011 e é ela que protagoniza os eventos narrados aqui. Os Kubheka são falantes de isiZulu e praticam o que chamam em inglês de "zulu culture", o que inclui a relação de comunhão e propiciação com/dos ancestrais por meio de uma série de rituais, como os avisos de mudança de casa, funerais e casamentos.

No que concerne ao casamento, os zulus são definidos como exogâmicos, com descendência patrilateral e residência patrilocal. Efetuam considerável prestação matrimonial do grupo de parentes do noivo para os parentes da noiva: o lobola - que corresponde a 11 vacas, mas é normalmente pago em dinheiro. Os filhos gerados em uniões consolidadas por este "pagamento" recebem o sobrenome paterno e residem com os parentes paternos, sem direitos junto aos parentes maternos ${ }^{4}$. O lobola é consorciado ao umembheso (presentes que o noivo entrega à família da noiva) e, em contrapartida a ambos, a noiva deve dar o umabo (presentes) à família do noivo - evento que encerra o casamento e confere posições a todos os envolvidos. Este conjunto de prestações matrimoniais celebra o que pode ser chamado de "casamento tradicional zulu".

\footnotetext{
${ }^{4}$ Sobre uma discussão mais aprofundada sobre o lobola e as relações efetivadas a partir desse prestação, assim como o modo como ela ocorre, ver Azevedo, 2015.
} 
No entanto, é necessário esclarecer que não há uma preeminência de "rituais tradicionais" sobre outros "coloniais", nem vice-versa. Como escreve Borges, "Besides the so-called traditional wedding [...], it is imperative to perform the colonial cerimony in a context where everyone is simultaneously Christian as Traditionally Zulu." (Borges, no prelo: 9). Dessa forma, o lobola, o umembheso e o umabo - prestações efetuadas entre os grupos de parentes dos noivos -, assim como o white wedding e o casamento civil - "rituais coloniais" - estão todos presentes nas práticas matrimoniais dos falantes de isiZulu nos dias atuais.

Este artigo dedica-se à análise do umabo, prestação matrimonial que havia ficado suspensa devido ao falecimento precoce da noiva e a outras intempéries que impossibilitaram a sua realização. Quando os Kubheka passaram a viver em um lugar seguro, a oportunidade de realizar o umabo surgiu no horizonte. Entretanto, o modo surpreende com que foi levado à cabo não corresponde simplesmente ao exotismo de uma neta que se coloca no lugar da avó durante a performance ritual. Parentes consanguíneos se passaram por afins e casas atuais fizeram as vezes de casas pretéritas para que todos, vivos e ancestrais, estivessem com propriedade na fazenda que os Kubheka conquistaram para viver.

Como ficará claro no final deste artigo, as fotografias dos Kubheka foram elementos importantes não somente por me darem a oportunidade de visualizar o white wedding realizado muitos anos antes da minha pesquisa ou por permitirem a discussão sobre casamentos de pessoas falecidas. A relação de afetividade com as fotografias, especialmente aquelas penduradas na parede - que são poucas, porém significativas -, nos falam de uma presença constante de pessoas falecidas nas casas em que se vive. Esses retratos, como foi possível perceber no final do trabalho de campo, também buscavam, como as pessoas, paredes firmes em que pudessem se sustentar. 


\section{As casas dos Kubheka}

O percurso de vida da família Kubheka tem início em Umkhamba, sua casa ancestral, isto é, o lugar em que estão enterrados os seus ancestrais na área rural de Ingogo, província de KwaZulu-Natal.

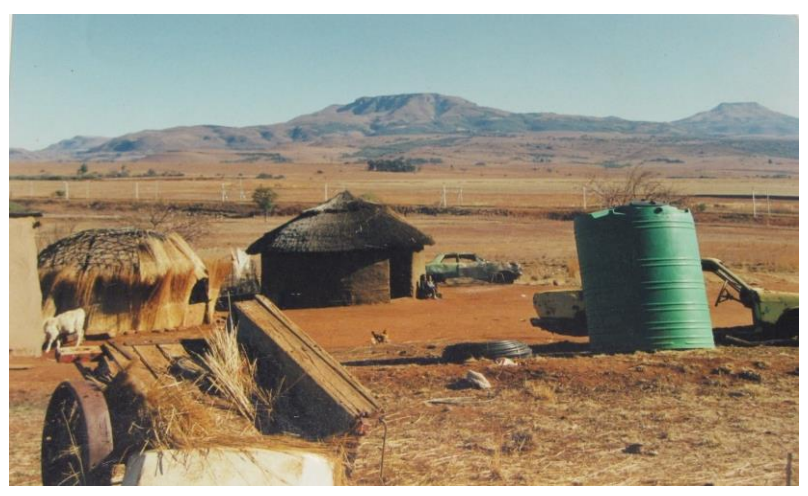

Umkhamba

Fonte: Arquivo Kubheka.

A família Kubheka vivia ali de acordo com os agreements (acordos) firmados com o fazendeiro branco dono da terra - que concediam o direito de morar em pequenos sítios - visto que durante o apartheid a posse de títulos fundiários era impedida a pessoas negras. Em Umkhamba, Mangaliso nasceu em 1950, mas logo foi levado pela avó paterna para viver em Thokosa, township nos arredores de Johanesburgo, província de Gauteng.

Foi em Thokosa que Mangaliso se casou com Sesi e teve quatro filhos. Indicativos como infraestrutura básica (água encanada e luz elétrica), escola para as crianças e emprego compunham o cenário em que a família Kubheka prosperava, vivendo em casa própria de alvenaria e possuindo uma frota de taxis (vans de transporte coletivo e alternativo).

Às vésperas da democracia, conflitos entre partidários do ANC - African National Party - e do IFP - Inkatha Freedom Party - levam à expulsão dos Kubheka de Thokosa para Ingogo 5 . De volta à Umkhamba na área rural de Ingogo, o acesso à escola

\footnotetext{
${ }^{5} \mathrm{O}$ momento histórico que precede as eleições democráticas na África do Sul é marcado por conflitos entre partidos apoiados pela população negra, como o ANC e o IFP. Esses conflitos, iniciados na década de 1980, ocorreram em todas as townships sul-africanas e até mesmo nas áreas rurais. $\mathrm{O}$ crescimento das rivalidades entre um partido de base étnica zulu - o IFP, encabeçado pela controversa figura de
} 
é o propulsor de uma nova mudança em direção a Madadeni, township dos arredores, em que as crianças vão estudar.

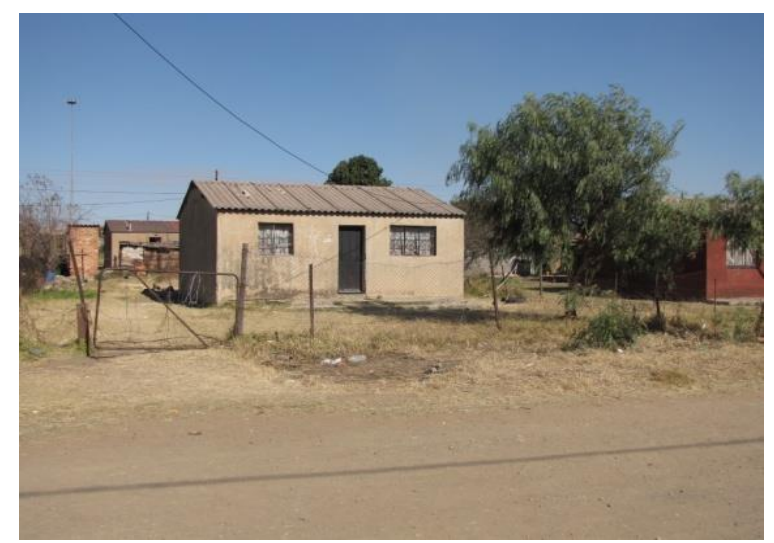

Uma das casas em que os Kubheka viveram em Madadeni

Fonte: Aina Azevedo.

Eventos como a morte trágica de Sesi, esposa de Mangaliso, e a impossibilidade de custear a vida naquela township levam os Kubheka novamente de volta à Umkhamba- a casa de seus ancestrais em Ingogo. Mesmo com o fim do apartheid e a implantação da democracia em 1994, os acordos entre moradores de fazenda e fazendeiros brancos não se mostram mais favoráveis aos primeiros. É neste momento que a família Kubheka passa uma longa temporada (quase uma década) em Umkhamba sob severas condições: sem energia elétrica, longe de fontes de água, proibidos de possuírem o número de cabeças de gado que consideravam imprescindível, e proibidos, ainda, de cruzar a propriedade dos fazendeiros brancos, dificultando o caminho das crianças à escola.

O longo percurso em busca de um lugar para viver chega ao fim na Tomato Farm, uma fazenda de brancos "redistribuída" aos Kubheka, à qual são incorporados alguns benefícios pelo programa de Land Reform, como estufas (nas quais atualmente cultivam tomates orgânicos sob a supervisão de um fazendeiro branco da região) e um rebanho de ovelhas (já que a fazenda originalmente estava organizada para a criação desses animais).

Mangusuthu Buthelezi, "chefe tradicional" do bantustão KwaZulu no apartheid - e outro mais universalista - o ANC de Mandela - desmantelava as possibilidades de transição para a democracia por meio de um "poder negro". 


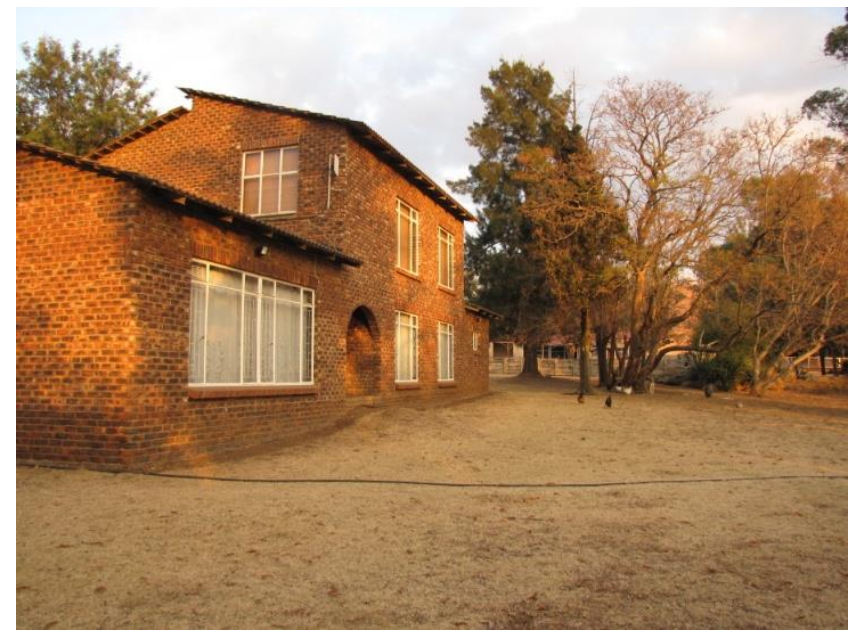

Tomato Farm

Fonte: Aina Azevedo.

Essas mudanças de casas e lugares são acompanhadas também pelas mudanças dos ancestrais dos Kubheka: mesmo enterrados em Umkhamba, eles devem sempre ser avisados sobre o novo lugar de morada por meio de um umsebenzi (ritual dedicado aos ancestrais). O valor atribuído aos novos lugares resulta não apenas das possibilidades de vida ali encontradas, mas também da possibilidade de realizar rituais que satisfaçam os ancestrais.

Sempre lembrados nas mudanças, os ancestrais não são meramente avisados, levados e trazidos. A não realização de um ritual pode ser tida como a fonte de problemas vividos pela família. Apesar de nunca ter deixado de avisar os ancestrais a respeito do novo lugar de morada, durante muito tempo a família Kubheka se viu impedida de finalizar um importante ritual de casamento: o umabo.

O caso dos Kubheka, embora muito particular - mas não único - não deixa de ser exemplar: ao não finalizarem um ritual de casamento - o umabo - devido ao falecimento de Sesi e aos imponderáveis de vidas marcadas por dificuldades, uma ancestral ficou no caminho. Sem ter se misturado apropriadamente aos Kubheka, a esposa de Mangaliso era avisada, bem como os outros ancestrais dos Kubheka, sobre os novos locais de morada, mas permanecia sozinha.

As mudanças de casas dos Kubheka, ocorridas por motivos diversos, têm uma singularidade que as aproxima das singularidades encontradas nas experiências de outras tantas famílias negras na África do Sul. Quer tenham iniciado seu desterro 
familiar devido aos forced removals (remoções forçadas deflagradas durante o regime do apartheid), pela simples busca da sobrevivência ou devido a conflitos políticos que inflamavam o país na antessala da democracia, o fato é que a quase todas as pessoas negras sul-africanas o direito de morar foi subtraído ou controlado durante praticamente todo o século XX. Impressa na vida dessas pessoas ficou a sensação de desterro familiar, "diásporas internas" (Vale, 2009: 73) ${ }^{6}$, insegurança e pendência em realizar rituais para aqueles que são imprescindíveis: seus ancestrais.

Como demonstra a literatura, as mudanças de casas não dizem respeito somente aos vivos. Conforme James (2007), os túmulos dos ancestrais constituem a "bandeira política" do ativismo pela Land Reform, o que denuncia a íntima relação entre ancestralidade e terra. E, em muitos momentos, falar sobre Land Reform é falar sobre a necessidade de ter acesso aos ancestrais. Ainda: na definição de Ntsebeza (2010), terra é sinônimo de identidade devido à profunda relação que guarda com a ancestralidade. A luta por terra e casa na África do Sul não se traduziria na luta por "moradia" e "trabalho" - como talvez seja o caso deflagrado por movimentos sociais como o Movimento dos Trabalhadores Rurais Sem-Terra no Brasil (Rosa, 2012); embora, também no Brasil, os movimentos indígena e quilombola sejam exemplos que transcendam a homologia entre terra-moradia-trabalho.

$\mathrm{Na}$ África do Sul, como observou Ntsebeza ${ }^{7}$, a terra foi um divisor de águas para a questão indígena entre o rural e o urbano, sendo o rural dividido entre fazendas de brancos e bantustões, e o urbano entre subúrbios de brancos e townships de negros. E, atualmente, as reivindicações por terra são sinônimo de agricultura, tanto para o governo, quanto para os estudos sociológicos que denominam o rural de agrário. No entanto, para as pessoas negras da África do Sul, a terra não é índice apenas de agricultura, mas de casa e identidade.

Embora os Kubheka experimentassem um momento de alívio e segurança desde 2009, quando foram beneficiados pelo programa de Land Reform e passaram a viver na Tomato Farm, a prosperidade almejada não poderia se traduzir somente em conquistas econômicas. Na verdade, o equilíbrio encontrado no lugar seguro para viver lhes

\footnotetext{
6 "Diásporas internas" é uma expressão empregada por Vale para definir o sofrimento que marca as mudanças, mortes e abandonos das mulheres com quem a autora trabalhou nas áreas rurais de KwaZuluNatal (2009, p. 73).

${ }^{7}$ Essas observações correspondem à palestra "Dilemas da cidadania na África do Sul pós-apartheid: a questão da terra", proferida pelo professor sul-africano Lugisile Ntesebeza, realizada no Departamento de Sociologia da Universidade de Brasília (20/08/2009).
} 
permitia dar prosseguimento àquilo que consideram imprescindível para a sua prosperidade, que são os rituais dedicados aos ancestrais, sejam eles de qual ordem forem. No caso dos Kubheka, havia uma relação íntima entre as mudanças de casas ao longo da vida, o casamento em aberto e a conquista de um lugar seguro para viver. Esta relação traduzia-se na oportunidade e necessidade de trazer para perto aqueles que foram deixados para trás ao longo de caminhos tortuosos.

\section{"Sempre que alguém pode fazer um casamento, faz"}

O desejo de Thembeni de realizar a parte pendente do casamento de seus pais permaneceu um assunto pouco mencionado ao longo dos primeiros meses de 2011, o que aumentava o sentimento de expectativa e dúvida quanto à sua realização. Enquanto trabalhava na construção civil na cidade de Newcastle, Thembeni silenciosamente juntava dinheiro e fazia empréstimos para realizar o casamento. Somente em junho de 2011 Thembeni anunciou que o umabo seria realizado no dia 2 de julho. Naquela altura, eu já havia participado de um outro casamento e presenciado a entrega do umabo exatamente o que estava para ocorrer na Tomato Farm, quando 52 pessoas da família Kubheka seriam presenteadas com cobertores, travesseiros e esteiras.

Mangaliso já havia pagado o lobola de Sesi, feito o umembheso (quando o noivo presenteia, com roupas, a noiva e sua família) e o white wedding; não fora ao umfundisi (padre) - como falava a respeito da cerimônia na igreja -, mas havia ido ao commisionary officce (cartório), quando realizou o casamento civil. Embora sempre procurasse fazer os rituais que lhe cabiam, Mangaliso não poderia dar presentes para si mesmo e o umabo deveria ficar a cargo de seus filhos.

Os presentes do umabo e do umembheso, assim como o gado/dinheiro do lobola constituem a classe especial de presentes que comunicam relações. As coisas dadas e recebidas falam sobre as expectativas sociais contidas naquilo que é trocado. Informam ainda sobre a capacidade de uns e outros receberem tanto quanto darem. No caso do umabo, se este evento tratasse simplesmente de presentes comprados e dados sem a intencionalidade de efetivar relações sociais e constituir as pessoas envolvidas, Mangaliso poderia, sim, dar presentes para si mesmo (para os Kubheka). No entanto, não importa somente comprar - o que em si já denota um esforço e atesta uma capacidade relacionada à confecção e à produção -, se trata igualmente de performatizar a troca de presentes, no caso a doação por parte de uns (a família da noiva) e a recepção 
por parte de outros (os Kubheka). Ainda: a produção do umabo ficara a cargo dos filhos de Mangaliso, porque eram eles, assim como o próprio Mangaliso, os mais interessados em constituir a pessoa da noiva. Suas vidas, suas casas e suas relações familiares dependiam do bem estar dessa ancestral feminina.

Para minha surpresa, uma semana antes do umabo, me disseram que deveríamos ir à Umkhamba - a terra ancestral dos Kubheka. De lá - depois de "falarmos" com os ancestrais - iríamos para Madadeni, onde dormiríamos, pois no dia seguinte haveria um umsebenzi (ritual dedicado aos ancestrais) na casa de Thembeni. Quando perguntei para Mangaliso por quê o umsebenzi não seria realizado na Tomato Farm, ele respondeu sem titubear: já que não poderiam viajar para Thokosa depois de falarem com os ancestrais em Umkhamba (lar ancestral dos Kubheka), o umsebenzi seria realizado na casa de Thembeni em Madadeni, que figuraria como a casa de seus "sogros" em Thokosa. O primeiro movimento que a noiva, enterrada em Umkhamba, deveria fazer, era ser direcionada à casa de seus próprios pais. Desse modo, o umsebenzi a recepcionaria na casa de Themebeni - como se fosse a casa de seus pais em Thokosa. Dali, a noiva poderia seguir, como se seguisse de sua própria casa de origem em Thokosa, para a casa de seu noivo - a Tomato Farm - com os presentes do umabo.

No umabo, a esposa de Mangaliso, enterrada em Umkhamba, deve ser levada à fazenda em que seu marido mora atualmente, a Tomato Farm. Para tanto, o caminho que conectará esses dois lugares será ritualmente homólogo ao caminho de suas vidas, e passará por Thokosa e Madadeni. Nesse percurso, há um retorno virtual a Thokosa lugar de origem da esposa de Mangaliso, Sesi Mollo, que ocorrerá, efetivamente, em Madadeni, onde a filha mais velha do casal mora atualmente.

A realização do umabo "tardio" transgredia a pretensa linearidade da vida, quando a esposa continuava o seu casamento mesmo depois de falecida. A arquitetura modernista do apartheid, com sua segregação espacial, temporal e social, era revisitada e reconectada. Ao recapitular as mudanças, os caminhos de suas vidas eram percorridos novamente através de suas casas. O passado de despossessões e o futuro de realizações a cumprir encontravam-se no momento presente, quando os protagonistas do umabo performatizavam os ausentes e percorriam, virtualmente, seus lugares de origem.

Em Umkhamba, Mangaliso "falou" com os ancestrais aproximando-se de seus túmulos. Os convocou para o umsebenzi que ocorreria em Madadeni e os avisou sobre a realização do umabo. Depois da evocação de Mangaliso, fomos para Madadeni levando ramos de árvores colhidos em Umkhamba e cuidadosamente enrolados em um 
sobretudo. Os ramos representavam a esposa falecida, assim como na fotografia em que um casal de noivos carrega ramos de árvores nas mãos indicando que estão no lugar de seus antepassados performatizando o seu casamento.

Ao chegarmos a Madadeni, fomos recebidos por Bongiwe, neta de Mangaliso, sentada em frente à casa, vestida com um xale quadriculado - adereço usado pelas noivas - e acompanhada por uma cabra. Thembeni entregou os ramos de árvore para Bongiwe que se levantou e entrou em casa com a cabra. Bongiwe sentou-se no chão recostada a uma das paredes da casa, ao lado da cerveja ofertada aos ancestrais, e ali permaneceu por mais ou menos duas horas. Durante este tempo, a cabra foi sacrificada do lado de fora pelos homens depois colocada no chão ao lado de Bongiwe. Sobre a cabra, uma sacola plástica branca guardava os ramos recolhidos em Umkhamba. No chão, havia ainda uma tina contendo o sangue sacrificial, uma caixa de fósforos e as cinzas da erva queimada para "falar" com os ancestrais. A presença dos ancestrais em qualquer casa exigia uma transformação do espaço que independia de sua forma original. A casa quadrada de Thembeni assumia contornos redondos por meio do espaço das oferendas para os ancestrais.

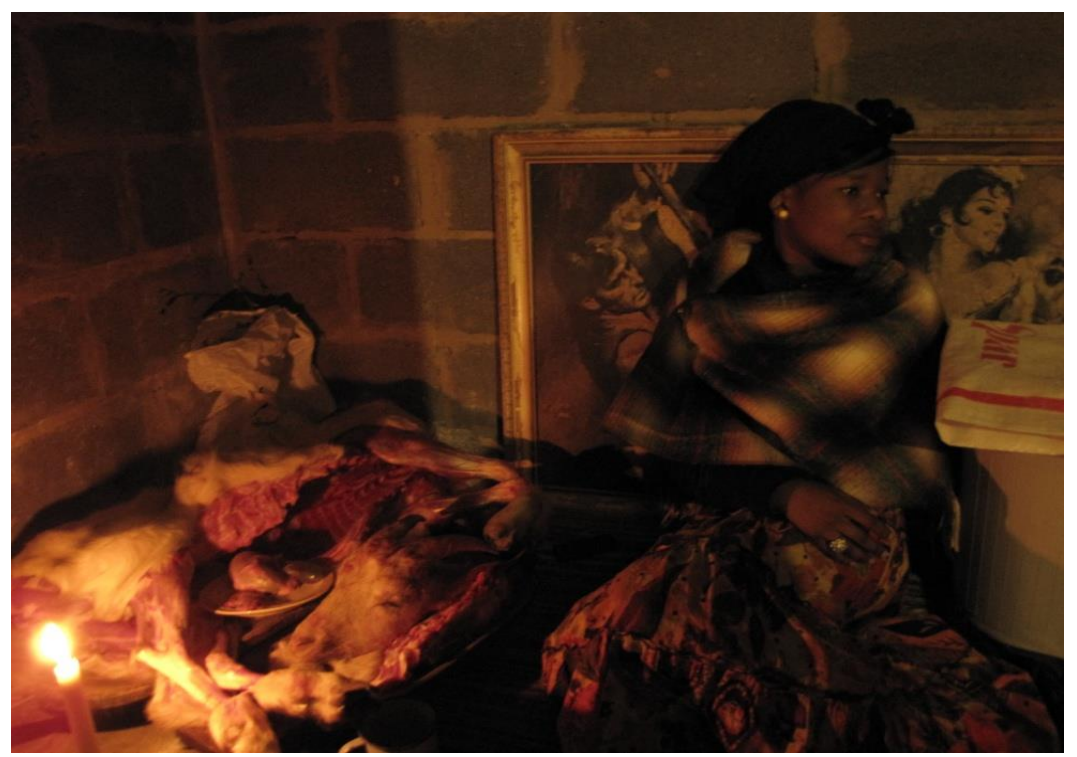

A noiva e as oferendas

Fonte: Aina Azevedo.

No dia do umabo, filhos e netos de Mangaliso, além de outros convidados, se juntaram para compor o cortejo da noiva que vinha em comboio de Madadeni. Os carros que chegaram à Tomato Farm trazendo as mais de 30 pessoas foram deixados próximo 
ao portão principal. O cortejo seguiu a pé e cantando, escoltado por uma caminhonete repleta de presentes do umabo.

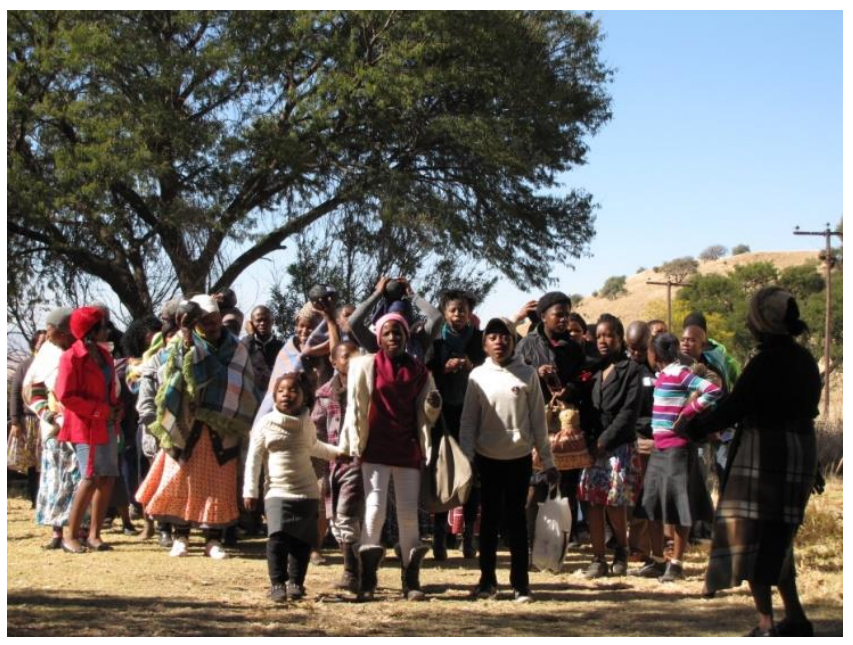

Cortejo do umabo

Fonte: Aina Azevedo

Durante a entrega de presentes, Bongiwe permaneceu sentada sobre uma esteira, acompanhada de parentes de sua mãe. A entrega do umabo seguia descontraidamente de acordo com a performance particular de cada presenteado. Ninguém hesitava em fazer algum tipo de graça e assim comover a platéia com risos de surpresa.

A última pessoa a receber o umabo foi Mangaliso. Bongiwe levantou-se e o convidou a levantar-se também. Depois o encaminhou para uma esteira em que ele se deitou o foi coberto por um cobertor, como havia ocorrido com todos os outros presenteados. Entretanto, quando Mangaliso levantou-se, embora procurasse fazê-lo com agilidade, as mulheres que representavam a família de sua noiva foram mais rápidas e o alcançaram, jogando talco nele e lhe dando varadas.

Depois disso, Mangaliso voltou a sentar-se. Bongiwe retirou os seus óculos e lambuzou a sua cara com hidratante, além de esfregar o seu corpo com uma toalha, como se lhe desse um banho. Em seguida, Bongiwe se preparou para servir chá para Mangaliso enquanto este brincava com o bule entornando-o na boca. Ao tentar retomar a seriedade, Mangaliso forjou, caricaturalmente, a existência real do líquido que consumia e tomou o seu chá. Antes de se retirar, Mangaliso ainda rebolou com as mãos na sua cintura larga e deixou a cena. 


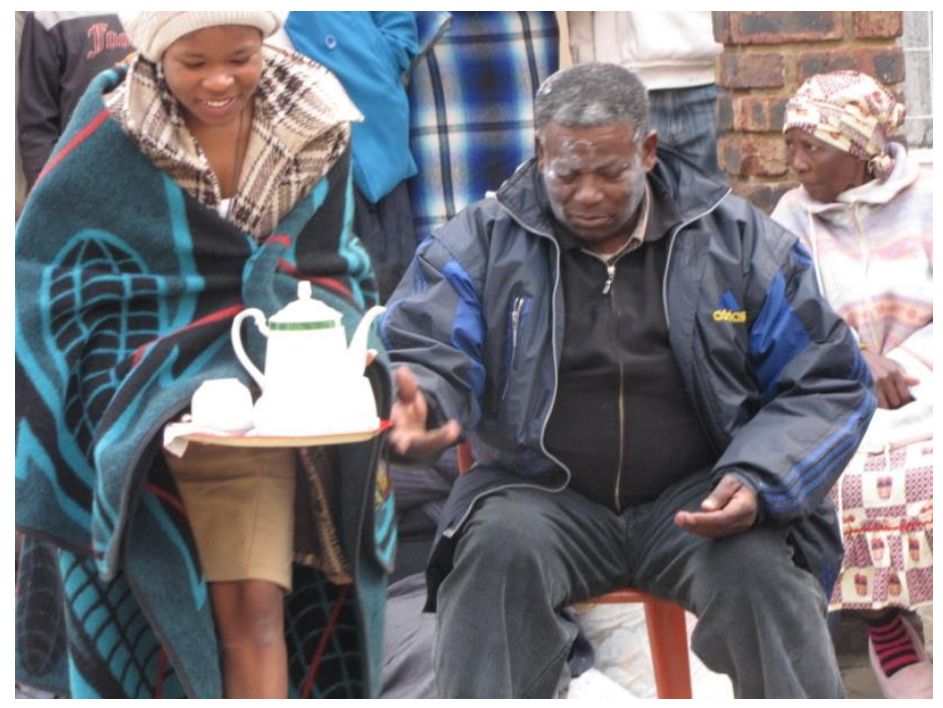

Bongiwe e Mangaliso

Fonte: Aina Azevedo

Com o fim do umabo, Bongiwe retirou seu cobertor de noiva das costas e passou a se comportar como se fosse ela mesma - não havia mais nenhuma observação ritual a ser seguida por ela a partir dali, e todos foram convidados a almoçar sob a tenda e arredores. O umabo havia terminado no meio da tarde e o almoço foi servido perto do sol poente. Depois do almoço, deu-se início à festa, ao som do kwaito eletrônico, propagado em alto volume por grandes caixas de som.

Após a chegada definitiva de Sesi à Tomato Farm, Mangaliso amanheceu gravemente enfermo. Mesmo assim, não poupou esforços e resolveu comparecer ao escritório do ANC (African National Congress) na cidade de Newcastle, quando já desempenhava suas atividades de counselor (uma espécie de vereador). Antonádia ${ }^{8}$ e eu o acompanhamos e, no final do dia, tivemos que levá-lo a uma clínica particular. $\mathrm{O}$ hospital público havia fechado e ele estava ardendo em febre.

\footnotetext{
${ }^{8}$ Antonádia Borges é professora no Departamento de Antropologia da Universidade de Brasília e foi minha orientadora durante o doutorado. Ela e Marcelo Rosa - professor no Departamento de Sociologia da mesma universidade - trabalham com Mangaliso e a família Kubheka desde 2005. Foi por intermédio deles que cheguei à África do Sul e, naturalmente, aos Kubheka. Na época em que ocorreu o umabo, Antonádia estava presente, além de Maíra Vale, amiga e antropóloga que fez pesquisa de campo na África do Sul em dois momentos de sua trajetória acadêmica (2009 e 2011).
} 
Mangaliso foi diagnosticado com início de pneumonia e saiu de lá tomando antibióticos. Em casa, permaneceu em repouso por dias, quando todos ficamos apreensivos. Afinal, Mangaliso jamais se deixava abater e, mesmo que se tratasse de uma pneumonia, a gravidade de sua situação parecia transcender a doença em si.

Quando recobrou a saúde, confessou para Antonádia: "You see. I really thought that the day after my marriage I would die and leave my wife widow!" Ao que Antonádia perguntou: "How could your dead wife became a widow?!" E ele respondeu: "How could she possibly be dead if just three days ago we finally got married?" (Borges, no prelo: 10).

\section{Ancestrais e Rituais}

Os princípios ontológicos que ancoram a cosmologia zulu definem os ancestrais ${ }^{9}$ como uma classe de agentes que pode influenciar positiva ou negativamente a vida dos viventes. Embora sua intenção seja sempre a de criar harmonia nas relações sociais entre os vivos, bem como entre os vivos e os mortos, quase sempre os ancestrais chamam a atenção dos vivos através de doenças, fracassos e toda uma série de infortúnios. Se comunicam com os viventes através de sonhos, presságios e animais como cobras - e são acessados pelos vivos por meio de um ritual chamado de umsebenzi, quando é possível "falar" com eles.

O umsebenzi pode ser definido brevemente como um ritual de propiciação que conta com o sacrifício de um animal (geralmente um bode ou uma cabra), o endereçamento de certas falas aos ancestrais e o compartilhamento de comida e bebida entre vivos e mortos. Além de promover a comunicação entre os vivos e os seus ancestrais, durante a confecção e a realização de um umsebenzi as pessoas que atendem ao ritual têm suas posições distinguidas pelo trabalho que executam e pela classe de

\footnotetext{
${ }^{9}$ Kopytoff argumenta que os ancestrais africanos são sobretudo elders, entendidos nos mesmos termos da categoria dos living elders ("seniores vivos") (Kopytoff, 1971: 138). Os Suku com quem ele trabalhou, inclusive, não teriam um termo que possa ser traduzido por ancestral. Os que já morreram são chamados bambuta, assim como aqueles que estão vivos - pessoas que atingiram a maturidade e têm "autoridade legal e mística" sobre os mais novos da sua "linhagem" (Kopytoff, 1971: 131). Berlund, por sua vez, trabalhou especificamente com os zulu e, assim como Kopytoff, é crítico ao uso do termo ancestral, posto que este não expressaria a relação de intimidade e de proximidade entre os que ficaram e os que partiram. Todavia, haveria uma diferença entre vivos e mortos - e o termo shadows ("sombras"), para este autor, serve para diferenciar aqueles que são os "mais velhos" em suas "linhagens" e não têm mais formas humanas visíveis (Berlund, 1989: 29 e 30). O termo amadlozi, tal qual usado pelas pessoas com que trabalhei, aproxima-se da definição de Berlund sobre as "sombras". Entretanto, neste artigo opto por chamar os amadlozi de ancestrais.
} 
comida e bebida que compartilham. Desse modo, um umsebenzi não trata somente da interação entre os vivos e os seus ancestrais: é também um ritual que cria, define e confere posições sociais a todos os sujeitos envolvidos, vivos e mortos.

White (2001) - que também fez pesquisa em uma periferia rural no norte de Kwazulu-Natal - descreve um evento em que a influência de um dos "avós" falecidos sobre o seu "neto" é tida como a causa dos infortúnios que esse vinha sofrendo. A vida do jovem S'khumbuzo era dificultada pela falta de emprego e, além disso, certa noite, ele foi atacado em uma briga de bar. Esses infortúnios fizeram com que a família consultasse um adivinho, pois notavam que o problema não se relacionava somente a uma dificuldade financeira e material. A conclusão do adivinho era de que o ataque sofrido por S'khumbuzo era um sinal enviado por um "espírito familiar" - o "irmão" de seu "avô" que, mais de trinta anos antes, foi procurar emprego nas minas em Johanesburgo e nunca mais voltou. O adivinho dizia que aquele homem fora agredido até a morte e seu corpo enterrado em alguma township daquela cidade. Agora, o falecido estaria tentando informar aos vivos que seu "espírito" errante não estava apto a retornar à casa até que um conjunto de ritos mortuários fosse feito em seu favor (White, 2001: 462).

O conjunto de rituais que S'khumbuzo deveria fazer para que ele mesmo pudesse seguir seu caminho com tranquilidade, remetia ao "espírito familiar" que há muito tempo havia partido. Sem conexão aparente com o presente, o modo como esse "espírito" viveu, morreu e seguiu a sua existência nômade vinha à tona e era apontado pelo "adivinho" como a fonte dos infortúnios que acometiam S'khumbuzo. Ao invés de uma história mal assombrada por um "espírito errante", o que a história de S'khumbuzo revelava é que os umsebenzi são sempre eminentes, porque a pessoa nunca termina, mesmo quando já morreu.

A eminência dos umsebezeni inscreve-se em uma temporalidade e uma espacialidade que não são lineares, cartesianas. Uma pessoa falecida há muito tempo e em um lugar distante ou mesmo desconhecido, pode ser conduzida à sua casa, caso os ritos mortuários não tenham sido realizados propriamente na ocasião da morte - como conta a história do familiar de S'khumbuzo. Além disso, mesmo que uma pessoa tenha recebido o tratamento que lhe é adequado na morte, ainda podem surgir infortúnios que são interpretados pelos viventes como eventos que guardam relação com algum de seus ancestrais. 
A relação entre os viventes e seus ancestrais nunca chega a um termo, pois a qualidade da pessoa - compreendida como um continuum entre os vivos e os ancestrais- nunca se estabiliza. Assim, o modo como "vivem" os ancestrais é crucial na vida dos viventes, que constantemente se angustiam por considerarem que há sempre um umsebenzi por fazer, quer se trate de uma "homenagem", um "funeral" ou de um casamento.

A relação dos viventes com os seus ancestrais é de reciprocidade, se inscreve no devir e faz da qualidade da pessoa algo inacabado. A profusão de umsebenzi exigidos pelos ancestrais e o anseio constante dos viventes em realizá-los significam que uma pessoa nunca está completa e que os umsebenzi são sempre necessários.

Os rituais de casamento guardam uma relação íntima com os ancestrais, que atuam tanto positivamente - trazendo prosperidade à união -, quanto negativamente causando infortúnios quando acontece de "faltar" algum ritual considerado imprescindível. Neste último caso, o tempo linear dos acontecimentos é sobrepujado, quando é possível retornar ao passado ou atualizar o futuro e realizar o ritual "pendente", tanto em se tratando do casamento entre os viventes, quanto do casamento entre pessoas que já faleceram.

O caso descrito por Granjo (2004 e 2005) sobre o lobolo de seu amigo Jaime ocorrido em Moçambique em 2003, é exemplar da relação de reciprocidade inscrita no devir mantida entre os vivos e seus antepassados, bem como da originalidade com que as pessoas lidam com as situações com que se deparam.

Jaime e Elsa - um casal com filhos e que morava junto há doze anos -, sentiram que os problemas conjugais que enfrentavam decorriam do não pagamento do lobolo por parte do noivo anteriormente: “[...] a sorte a que tinham direito - individualmente e como casal - estava a ser 'congelada' pelos espíritos dos antepassados, devido a estarem em falta para com eles" (Granjo, 2005: 58). O casal então decide que ambos (e não somente o noivo) irão juntar dinheiro para pagar o lobolo, a fim de encontrar a sorte que tanto almejam.

Na história de Jaime e Elsa, a transformação ritual é do próprio casal. Trajando sua roupa nova, Jaime participa de uma festa, após o pagamento do lobolo, quando é apresentado à família da noiva "[...] não enquanto pessoa abstrata, mas enquanto a nova pessoa em que se transformou". E Elsa, a noiva, só é "entregue" na casa do marido no dia seguinte, pois ainda receberia de sua mãe e de outras mulheres mais velhas conselhos sobre sua "futura" vida de casada (Granjo, 2005: 42). 
Em outras ocasiões, a transformação ritual é das pessoas falecidas, quando os viventes colocam-se no lugar de outros ausentes, sobrepujando o tempo e o espaço, a fim de realizar aquilo que seus ancestrais não puderam fazer em vida. Como explica White, retomando a história de S'khumbuzo e acrescentando um "ritual de casamento":

\begin{abstract}
"Looping or collapsing time is in fact a very common theme in the temporality governing rites of passage in these parts, where life cycles and their ritual representations are more often out of step than contemporaneous. (...) The issue in almost all such events is that some sort of misfortune draws attention to an omission that has hollowed out an earlier moment in time. (...) Some or even all of the people implicated within that original moment might be dead, and then the living have to take their places in time and to carry their absent bodies through the motions of an appropriate performance. A young man might thus find himself, quite literally, following in his late grandfather's footsteps as he faces his elderly grandmother in a dance to recapitulate a wedding that first happened fifty years before he was born" (2001: 464).
\end{abstract}

Nesses casos, não se trata somente de uma dificuldade enfrentada pelos vivos como na história de Jaime e Elsa que vêem a necessidade de casar e transformar a sua própria condição perante seus familiares e seus antepassados, se trata da própria insatisfação dos ancestrais em relação à incompletude de rituais considerados fundamentais para eles mesmos enquanto pessoas. No caso do "espírito familiar" de S'khumbuzo, era necessário refazer virtualmente os caminhos que o levaram à morte o trabalho nas minas em Gauteng durante o apartheid - e conduzi-lo à sua casa em KwaZulu-Natal.

A história da família Kubheka que representa o foco deste artigo, destaca-se pelas inúmeras mudanças de casa ao longo de sua vida, bem como pela "falta" de uma das partes que compõe o casamento entre os zulus. Quando os Kubheka têm a oportunidade de realizar a parte pendente do ritual, além da noiva já ter falecido - o que significa que outros devem estar em seu lugar -, os protagonistas do evento recapitulam os caminhos percorridos pela noiva quando estava viva e os caminhos que a levaram ao seu túmulo, para finalmente conduzi-la à casa do seu noivo.

O que o caso de S'khumbuzo, o da família Kubheka e provavelmente muitos outros revelam é que a constituição da pessoa não se refere somente à coerência do parentesco que relaciona S'khumbuzo a seu ancestral em linha paterna, bem como os 
Kubheka a essa mulher que é noiva (ou seja, uma estrangeira ${ }^{10}$ que precisa ser "domesticada" através do casamento) e, ao mesmo tempo, ancestral (a mãe/avó falecida dos descendentes dos Kubheka). Se esses mortos requerem rituais para que suas noções de pertencimento, bem como a de seus descendentes ganhem os contornos desejados, esse pertencimento relaciona-se também a experiências relacionadas ao apartheid e ao pós-apartheid.

A referência ao apartheid e seu legado de mudanças de casas, não são meros cenários ou lembranças das quais é possível se livrar tão facilmente. E, na verdade, o que a realização de rituais como esses nos mostra é que as próprias pessoas não parecem querer se despir dos sujeitos históricos que são, como se somente o parentesco coerente pudesse salvá-las. Ou seja, não é possível a um morto que se perdeu no caminho, ser honrado sem refazer virtualmente o percurso que o levou à morte incerta e que o trará de volta a sua casa. Como também não é possível finalizar um casamento como se isso fosse um capricho e não uma conquista cosmológica que relaciona um tempo de mudanças, sofrimentos e perdas a uma nova casa, a uma nova vida, onde finalmente, vivos e ancestrais podem morar com tranquilidade.

\section{Retratos na parede e paredes como retrato}

O mesmo retrato pendurado em duas paredes/casas distintas expressa bem o que a realização do ritual de casamento significava para a família Kubheka. Na primeira situação, Sesi, já falecida, tem seu retrato pendurado na parede da casa de Umkhamba (área rural em que estão enterrados os ancestrais dos Kubheka), onde seu marido e seus filhos passaram a viver desde que lá realizaram o seu funeral. Essa parede - como a casa, feita de mistura de barro e esterco de vaca - logo veio abaixo: paredes rachadas, que não sustentavam sequer retratos de entes queridos, não poderiam expressar melhor o desejo nutrido pela conquista de uma casa, capaz de abrigar solidamente as pessoas e seus sonhos de comunhão.

\footnotetext{
${ }^{10}$ Gluckman aponta que o princípio da patrilinearidade entre os zulus - sucessão de status e propriedade, bem como filiação - são direitos reconhecidos através de "uma mulher não aparentada consanguineamente" (1982: 222). Radcliffe-Brown, por sua vez, endossa essa mesma observação e escreve que os nuer e os zulus tem a "posição social do filho" determinada pela mãe, embora ambas as sociedade sejam "profundamente patrilineares" (1982: 89). Gluckman e Radcliffe-Brown seguem a observação de Evans-Pritchard de que "o princípio social da filiação agnática [...] se traça através da mãe" (cf. Gluckman, 1982: 222).
} 


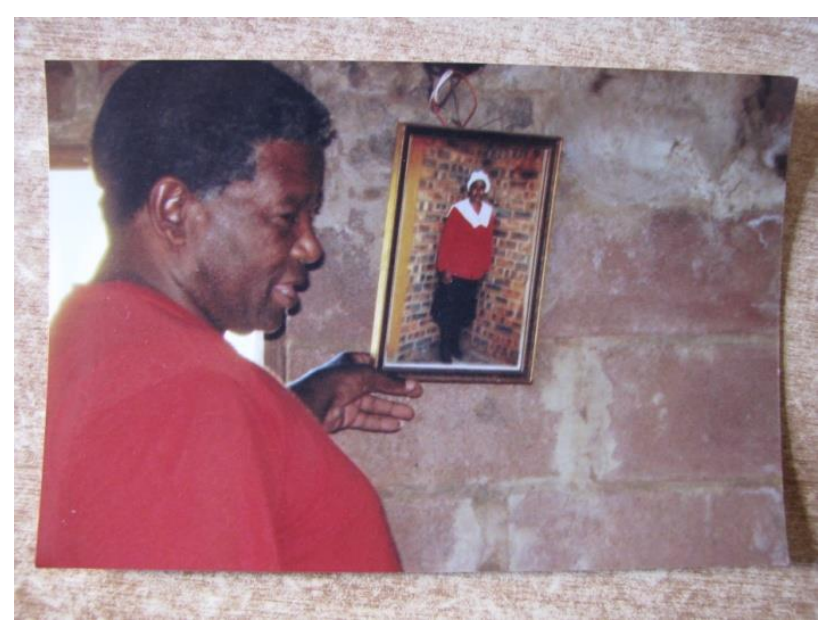

Retrato de Sesi na parede de Umkhamba

Fonte: Arquivo Kubheka

Na outra situação, Sesi não está somente pendurada na parede da Tomato Farm: ela parece estar lá, pelo simples motivo de que os tijolos que compõem o fundo de seu retrato e o da parede escolhida para pendurá-lo serem os mesmos. Essa dubiedade e coincidência me fizera crer, cotidianamente, que Sesi chegara a morar na Tomato Farm. A todo momento a via conosco, naquela casa, para depois ser capturada pela linearidade dos fatos e relembrar que ela jamais estivera lá.

O caráter holográfico daqueles tijolos sobrepostos dava conta de uma série de experiências e desejos que, finalmente, se consolidavam. Conquistava-se uma casa para abrigar aqueles que outrora estiveram suspensos - como os próprios viventes -, em busca de uma parede sólida o suficiente para sustentá-los a todos.

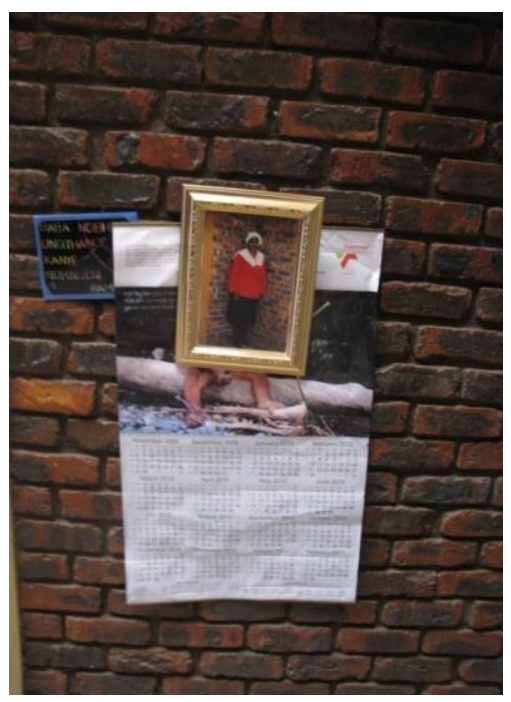

Retrato de Sesi na Tomato Farm

Fonte: Aina Azevedo 


\section{Referências}

AZEVEDO, Aina. Cosquistas cosmológicas: pessoa, casa e casamento entre os Kubheka de KwaZulu-Natal e Gauteng, p.346, 2013. Tese (Doutorado em Antropologia Social) Programa de Pós-graduação em Antropologia Social, Universidade de Brasília, Brasília. http://www.scribd.com/doc/213455720/2013-AinaGuimaraesAzevedo

AZEVEDO, Aina. "Se você quiser me lobolar" - Considerações sobre o na África do Sul contemporânea. Cadernos Pagu, Campinas, v. 45, jul/dez, p. 21-49, 2015.

BERLUND, Axel-Ivar. Zulu Thought-Patterns and Symbolism. Bloomington and Indianapolis: Indiana University Press, 1989 [1976].

BORGES, A. Land and the ritual production of hope: an ethnographic account on mutality and conviviality among living and dead in South Africa. Revista Africa, no prelo.

GLUCKMAN, M. Parentesco y Matrimonio entre los lozi de Rodesia del Norte y los zulúes de Natal. In: RADCLIFFE-BROWN, A. R.; DARYLL, F. Sistemas Africanos de Parentesco y Matrimonio. Barcelona: Anagrama, p. 185-233, 1982.

GRANJO, Paulo. O lobolo de meu amigo Jaime: um velho idioma para novas vivências conjugais. Travessias, n.. 4/5, p. 47-78, 2004.

Lobolo em Maputo. Um velho idioma para novas vivências conjugais. Porto:

Ampo das Letras. 2005.

JAMES, D. Gaining Ground? 'Rights' and 'Property' in South African land reform. Abingdon, Oxon: Routledge Cavendish, 2007.

KOPYTOFF, Igor. Ancestors as elders in Africa. Africa, v. 41, n. 2, p, 129-142, 1971.

NTSEBEZA, L. Reconciliation and the land question. In: DU TOIT, F.; DOXTADER, E. In the Balance - South Africans debate reconciliation. Johannesburg: Jacana, 2010.

RADCLIFFE-BROWN, A. R. Introducción. In: RADCLIFFE-BROWN, A. R.; DARYLL, F. Sistemas Africanos de Parentesco y Matrimonio. Barcelona: Anagrama, p. 11-97, 1982.

ROSA, M. Reforma agrária e land reform: movimentos sociais e o sentido de ser um sem-terra no Brasil e na África do Sul. CADERNO CRH, Salvador, v. 25, n. 64, p. 99-114, jan./abr. 2012.

VALE, M. Transbordando Antropologias: mulheres, morte e poder na África do Sul. 2009. Monografia (Graduação em Ciências Sociais) Departamento de Antropologia, Universidade de Brasília, Brasília.

WHITE, Hylton. Tempora et Mores: Family Values and the Possessions of a Post-Apartheid Countryside. Journal of Religion in Africa, v. 31, n. 4, p. 455-470, 2001. Published by: BRILL Stable URL: http://www.jstor.org/stable/1581469 Accessed: 11/05/2010 09:04

Recebido em: 17/11/2015. Aprovado em: 19/12/2015. 